\title{
SHORT COMMUNICATION \\ BIOTECHNOLOGY INFORMATION IN EUROPE: A SYNOPSIS OF THE FINAL REPORT FROM THE BIOTECHNOLOGY INFORMATION STRATEGIC FORUM
}

\author{
JACK FRANKLIN \\ ASFRA BV, Voorhaven 33, 1135 BL Edam, The Netherlands
}

INTRODUCTION

Advances in any branch of science, including those related to the diagnosis and understanding of human disease, are of little value unless they can be promulgated efficiently. Increasingly, this depends upon the use of electronic data collection and retrieval systems. Information technology is therefore an integral component of this journal's subject matter and developments in this field are of immediate relevance to its readership.

As discussed in an earlier review (Franklin, 1994) users and providers of Biotechnology Information are faced with both opportunities and problems arising out of the rapid pace of development in the Bio-informatics field. Some of the concerns have a specifically European dimension; for example, since legal issues (copyright, intellectual and property ownership) may require different solutions in different settings, the operations of individual databases and networks may have to be tailored to particular environments. However North American systems and practices currently dominate the field and, through economies of scale, might undercut any alternative developments.

The Biotechnology Information Strategic Forum (BTSF) was formally established in December 1992 to examine emerging problems from the "information producers" " point of view, but also to ensure that the databases and similar products on offer suit the needs of their users. The Forum has been based on a core group (listed below) of commercial organisations and academic institutions.

\section{BTSF CORE GROUP}

C A B International (UK)

Elsevier Science B.V.: EMBASE (NL)

INIST: PASCAL, (France)

Derwent Publications Ltd., (UK)

Wolters-Kluwer Academic Publishers (NL)

Pergamon Press, UK imprint, and member of Elsevier Science B.V.

Springer Verlag (Germany)

Royal Society of Chemistry (UK)

J Wiley and Sons (UK)

The European Bioinformatics Institute (UK)

INSERM/CERDIC (France) 
Working closely with a widening community of biotechnology information users, the Forum has undertaken a number of tasks, namely to:

- identify user needs through interactions with industrial users in different market sectors, with advisory groups and with individual purchasers/users.

- assess these needs in relation to commercial, technical and regulatory constraints.

- examine potential solutions to market-led questions (e.g. modifications to individual projects/products that might increase their compatibility and so lead to an overall increase in usefulness. This could involve inter-linking of accession numbers, changes to thesauri, joint files from different producers on common delivery mechanisms, and so on.)

- develop mechanisms for the support of non-commercial products (e.g. R\&D databases, National Biotechnology Associations products).

- strengthen the European information industry's response to market and political demands in the field of international bioinformatics.

- establish the BTSF as the formal, permanent focal point for European Biotechnology information.

- identify legal issues in this area and suggest necessary research with a view to changes in international copyright and intellectual ownership laws.

\section{OPERATIONS}

The BTSF met eight times during 1993 and 1994. Between formal meetings, task forces working on: user needs, copyright and legal matters, and database links, used electronic mail and associated conferencing techniques as well as conventional meetings to debate and pursue their specific remits.

The outcomes of these deliberations were debated in full meetings of the members, and also two "invited" User Workshops which brought together commercial and academic users and producers.

A major outcome of their meetings was the clear identification of the divisions between the academic and commercial R\&D communities on the use of networks and databases for biotechnology research. Nevertheless both communities must use the same databases and services and it is clearly essential for European Biotechnology R\&D that they co-operate to make best use of the resources on offer. The BTSF has therefore made an increased effort to ensure that the results of their deliberations are made available to other organisations debating the same and related issues. Contacts have been established with "formal" user committees including the Pharma Documentation Ring (PDR), a grouping of 30 top European Pharmaceutical companies, and the European Chemistry Industry Council's (CEFIC) Scientific and Technical Information Working Party. Representatives have also been sent to subsequent bioinformatics strategy meetings including the EMBnet organised Strategies in Bioinformatics meeting held in September 1994 (available on the WWW at http://www.no.embnet.org/nijmegen/index.html).

\section{DEVELOPMENTS IN SPECIFIC AREAS}

\section{Database hosts}

Early attempts to open a meaningful dialogue with the commercial database hosts were unsuccessful, and this was a disappointment. Recently however, contacts have 
improved greatly and the German medical information host DIMDI has agreed to participate in future activities. At the same time, a great deal of biotechnology information is mounted upon academic hosts and these might offer the market an alternative and efficient solution to obtaining information, especially where specialised software tools and expertise are required to access and use the data optimally. Examples already exist (e.g. in the Netherlands, the UK and France) where university-based computer centres offer databases to the academic and - increasingly — industrial sectors. Well designed cooperative agreements between academic and commercial database hosts, with appropriate confidentiality and fee-paying services installed, could allow Europe to offer producers a larger platform to mount databases, giving users better access — in some cases according to well established market definitions which would allow better user support.

\section{Networks}

The BTSF, like many other user and producer groups, is anxious that European networks be improved. Industrial users in particular, require good network security and efficiency; the present academic networks are inferior on both counts and yet many of the databases industry requires (nucleotide and protein sequences, genetic maps etc) are only available via the academic networks. Steps must therefore be taken to resolve these apparent difficulties as, for instance, in the UK, where the NHS' Wide Network Project has established confidential secure private networks for the medical profession with secure and confidential gateways to the internet.

The biology market of producers and users has often been ignored by the networking community but recent attempts to meet with European networking initiatives in the private (British Telecom) and public (DANTE and the CEC DG XIII staff) sectors have been useful.

The increasing use of networks is opening up new problems of copyright and legal ownership. In the US, the green paper 'Intellectual property and the National Information Infrastructure' prepared by Bruce A Lehman, Assistant Sectretary of Commerce and Commissioner of Patents and Trademarks, looks like being a landmark for future use of networks for scientific and other information. A common European response has yet to emerge but BTSF has established a Copyright and Legal Committee to examine such issues and to liase with user groups.

\section{Databases}

Thses are expensive to build and to maintain. The explosive growth rate of the Internet and the absence of a clear legal framework to regulate ownership and copyright has led to unstructured - and hence inefficient - expansion.

Biology databases vary in content, structure and usability. Many are built from submissions from the academic world and perceived wisdom holds that raw data (freely contributed to the database) must be available for the lowest possible price, whereas value added to information can be charged for. Establishing rules that will protect the investment of information producers, while encouraging them to make their databases widely available through easily accessible networks, is one of the tasks that BTSF has set itself and upon which it will work with the Commission of the European Union.

\section{Education}

BTSF has identified this as a priority. All users, especially those in small and medium-sized industrial enterprises, need educating in the use of informatics. 
Universities are often best suited to meeting this need, with their well-organised computer and associated information technology departments. The same is often true of large companies but, overall, the use made by the 'market' of bioinformatics falls far short of its full potential.

\section{RECOMMENDATIONS}

The final report of BTSF (available in full from the author) concluded with the following recommendations.

1. Steps should be taken to improve the market position of European database hosts and database producers in the face of competition from large, subsidised, US competitors. The specific requirement of the biotechnology community is for continued availability of a wide range of specialised databases.

2. The European biotechnology community should act together as a group to ensure that their requirements for reliable, high bandwidth networks are met.

3. The requirements of BTSF members should be included in Europe's response to US proposals on intellectual property.

4. Projects should proceed to explore the potential of using existing software to link bibliographic and factual databases in biotechnology so as to provide a unified interface for users in a way that meets their identified needs.

5. Co-operative agreements should be sought between commercial and university sectors to enable the building of "tanks" of specialised (often small) databases in biotechnology, with new models for selling data.

6. The BTSF should continue as a formal, permanent focal point for European biotechnology information. It should be a self-financing organisation with membership open to information providers, publishers, database hosts and users in the commercial and non-commercial sectors in the countries of the EU. It should establish high level groups to prepare presentations on key strategic issues and take part in joint $\mathrm{R} \& \mathrm{D}$, industrial, educational and legal projects to test strategic hypotheses and stimulate education so as to promote the use of the many products and services on offer.

\section{REFERENCE}

Franklin, J. (1994). Bioinformatics and biotechnology information - some moves in Europe. Disease Markers, 12, 11-21. 


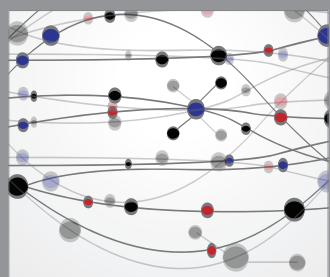

The Scientific World Journal
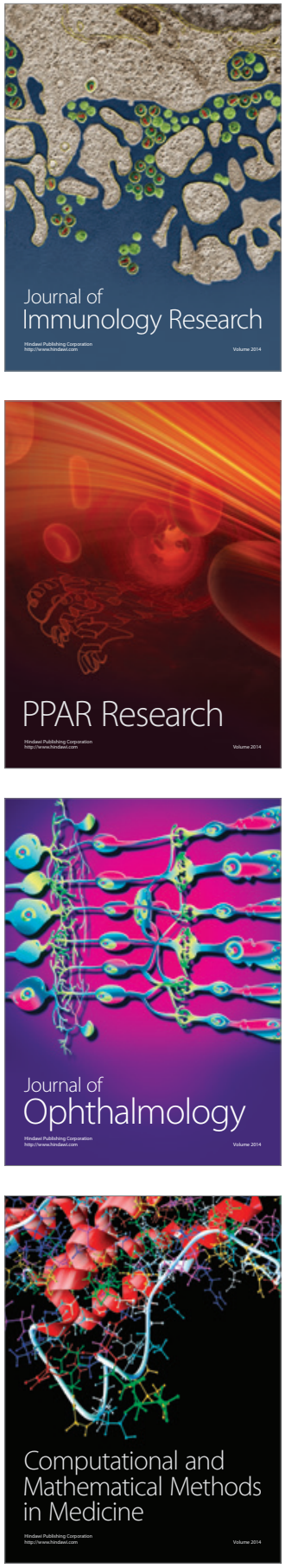

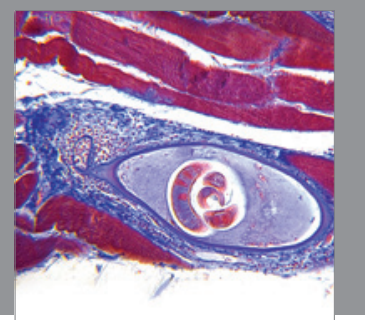

Gastroenterology

Research and Practice
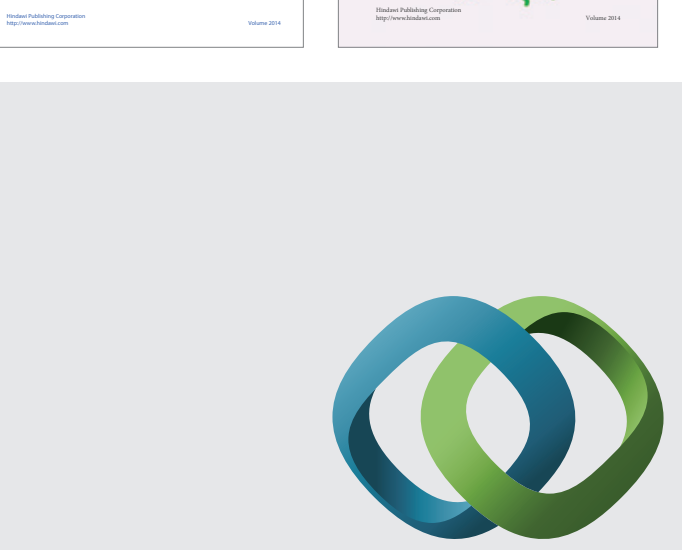

\section{Hindawi}

Submit your manuscripts at

http://www.hindawi.com
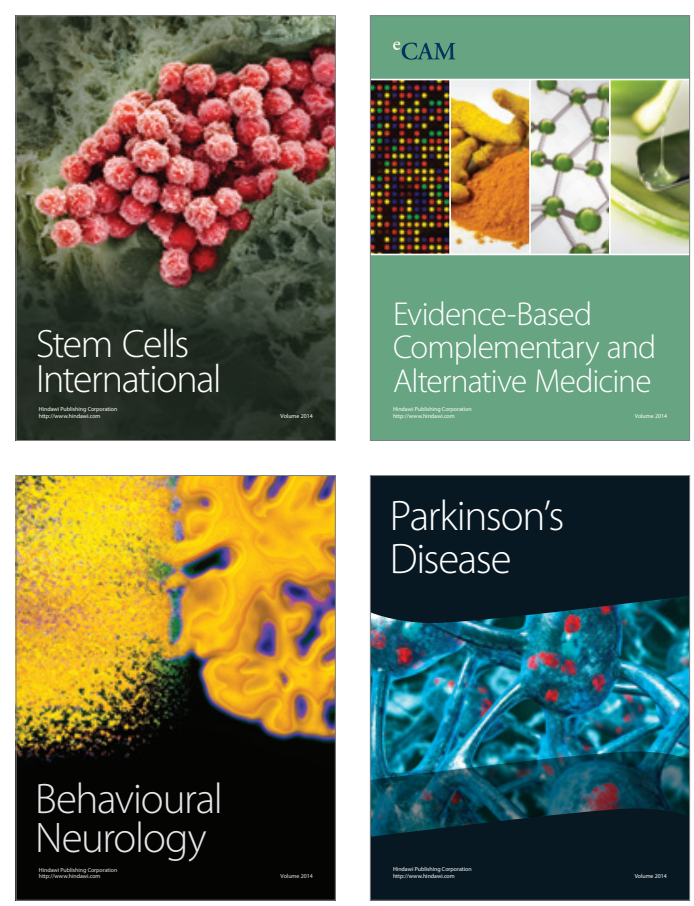

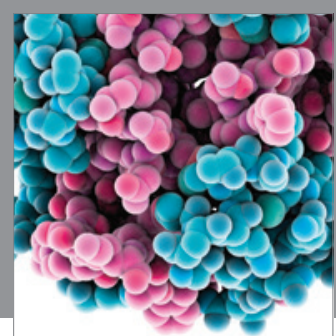

Journal of
Diabetes Research

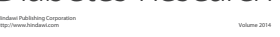

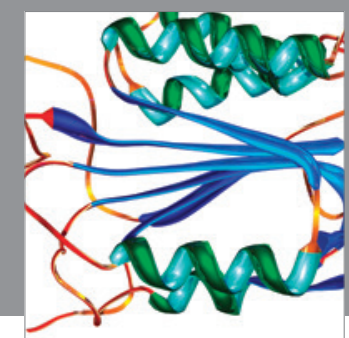

Disease Markers
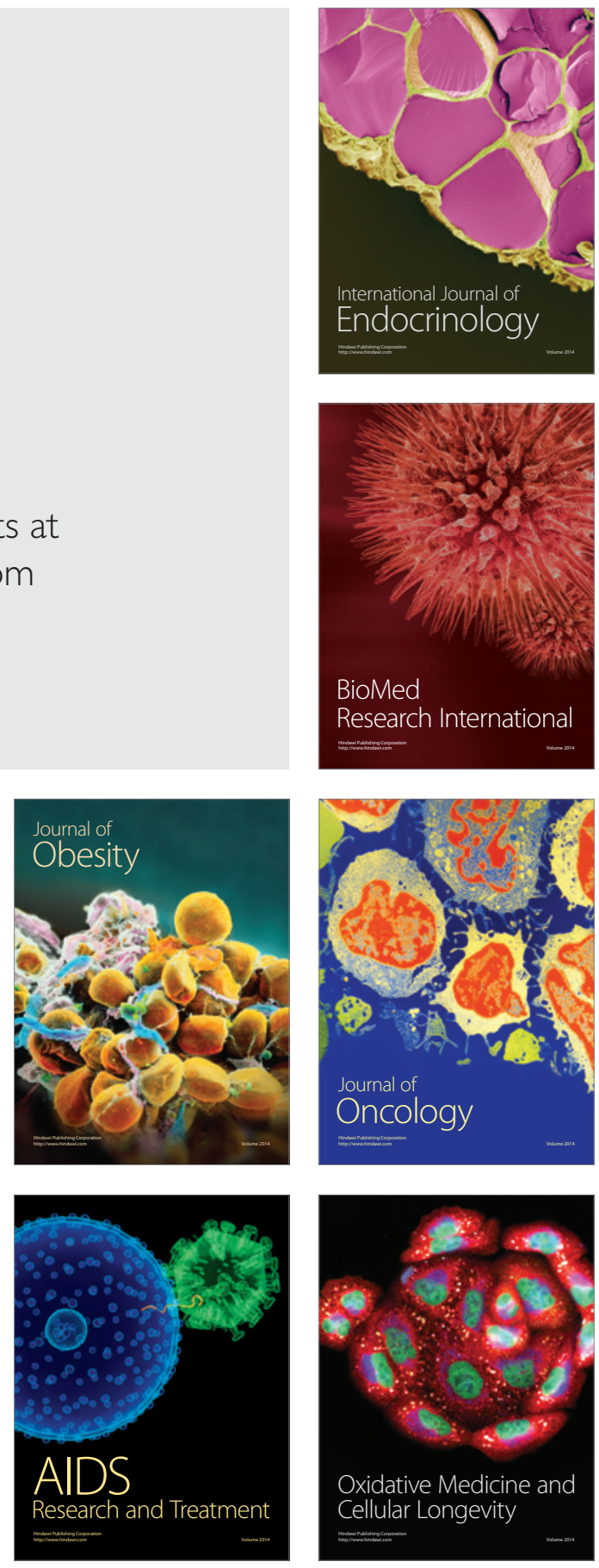